\title{
Psicooncología
}

ISSN: $1696-7240$

\section{Rumination and social support as predictors of posttraumatic growth in women with breast cancer: a systematic review}

Carolina Villanova Quiroga ${ }^{1}$; Laura Fritzen Binfaré2; Tânia Rudnicki³; Irani Iracema de Lima Argimon ${ }^{4}$

Recibido: 23 de abril de 2018 / Aceptado: 20 de agosto de 2018

\begin{abstract}
Objective: Posttraumatic Growth (PTG) is a perceived positive change after a stressful situation. Studies describe different predictors of PTG. The purpose of this study was to (1) review the evidence that rumination and social support are predictors of PTG; (2) analyze the results of the screened studies. Method: A systematic review was conducted by searching for articles with quantitative or mixed methods that evaluated PTG using the Posttraumatic Growth Inventory, rumination and/or social support in women with breast cancer. Results: Were identified twelve articles that corresponded to the inclusion criteria. All of them reported some degree of PTG in their samples. Rumination was evaluated in three studies, social support was evaluated in ten, and both were considered to have a positive correlation with PTG. Conclusions: This review concludes that rumination and social support are predictors of PTG in women with breast cancer. These results contribute to the development of new interventions in mental health.
\end{abstract}

Keywords: Health psychology; Posttraumatic growth; breast cancer; social support; rumination.

\section{[es] Ruminación y apoyo social como predictores del crecimiento postraumático en mujeres con cáncer de mama: una revisión sistemática}

Resumen: Objetivo: el crecimiento postraumático (CPT) es un cambio positivo percibido después de una situación estresante. Los estudios describen diferentes predictores de CPT. El propósito de este estudio fue (1) revisar la evidencia de que la rumiación y el apoyo social son predictores del CPT; (2) analizar los resultados de los estudios seleccionados. Método: Se realizó una revisión sistemática mediante la búsqueda de artículos con métodos cuantitativos o mixtos que evaluaron CPT por médio del Inventario de Crecimiento Postraumático, rumiación y/o apoyo social en mujeres con cáncer de mama. Reesultados: Se identificaron doce artículos concernientes a los criterios de inclusión. Todos informaron algún grado de CPT en sus muestras. La rumiación se evaluó en tres estudios, el apoyo

1 Carolina Villanova Quiroga - Pontifícia Universidade Católica do Rio Grande do Sul.

E-mail: carolina.quiroga@acad.pucrs.br

2 Laura Fritzen Binfaré - Pontifícia Universidade Católica do Rio Grande do Sul.

E-mail: laura.binfare@acad.pucrs.br

3 Tânia Rudnicki - Centro Universitário da Serra Gaúcha

E-mail: tania.rudnicki@gmail.com

4 Irani Iracema de Lima Argimon - Pontifícia Universidade Católica do Rio Grande do Sul

E-mail: argimoni@pucrs.br

* Dirección de correspondencia: Ipiranga Avenue, 6681, building 11, room 908 - Partenon neighborhood - Porto Alegre city / state of Rio Grande do Sul - Brazil. Zip Code: 90619-900.

E-mail: carolina.quiroga@acad.pucrs.br 
social en diez, y se consideró que ambos tenían una correlación positiva con CPT. Conclusiones: Esta revisión concluye que rumiación y apoyo social son predictores de CPT en mujeres con cáncer de mama. Estos resultados contribuyen al desarrollo de nuevas intervenciones en salud mental.

Palabras clave: Salud psicológica; crecimiento postraumático; cáncer de mama; apoyo social; rumiación.

Sumario. 1. Background 2. Methods 2.1. Data extraction 3. Results 4. Discussion 5. Conclusions 6. References.

Cómo citar: Villanova Quiroga C, Fritzen Binfaré L, Rudnicki T, Iracema de Lima Argimon, I. Rumination and social support as predictors of posttraumatic growth in women with breast cancer: a systematic review. Psicooncología 2018;15:301-314. doi: 10.5209/PSIC.61437.

\section{Background}

In 1996, Richard Tedeschi and Lawrence Calhoun started publications on Posttraumatic Growth - PTG, a construct that shifts the focus of investigations into the theory of pathogenesis, searching to deepen aspects of adverse situations. PTG deals with a positive cognitive remodeling, resulting from experience of a situation perceived as stressful and/or traumatic. It involves five different aspects, including Relating to Others, New Possibilities, Personal Strength, Spiritual Change and Appreciation of Life, evaluated in the Posttraumatic Growth Inventory (PTGI) ${ }^{(1)}$. This model states that the event affects the belief system of a person. From this, people will present different strategies and behaviors to face the situation, as psychic and/or social order ${ }^{(2)}$.

The model has been tested in studies with different populations and different diagnoses of organic diseases, such as rheumatoid arthritis ${ }^{(3)}$. Within the oncology area, PTG has been associated with head and neck cancer( ${ }^{(4)}$, oral cavity cancer ${ }^{(5)}$, breast cancer ${ }^{(6)}$, hematological cancer ${ }^{(7)}$ and pediatric cancer ${ }^{(8)}$. Thus, the possibility of developing and perceiving positive aspects from adverse situations has been proven.

Cancer is the name given to a large set of diseases characterized by the uncontrolled proliferation of malignant cells, which can reach any part of the human body. Clustering of these cells can cause malignant tumors or neoplasms. In 2015, cancer was considered the second largest cause of death in the world, responsible for 8.8 million cases. In men, the most common types of cancer are prostate, lung and colorectal. In women, the most frequent are breast, colorectal and lung cancer ${ }^{(9)}$.

Breast cancer is the most prevalent diagnosis in women worldwide, reaching approximately 1.5 million people per year. It also presents the highest death rate among women with cancer. In 2015, 570.000 women died from breast cancer ${ }^{(9)}$. Its diagnosis and treatment has a direct effect on the mental health of the carrier, which can result in symptoms such as depression and anxiety ${ }^{(10-12)}$. Negative symptoms sometimes persist significantly after the end of medical treatment ${ }^{(13)}$. Thus, it is important evaluation and assistance in the mental health area in this population.

The studies of PTG on women with breast cancer found different associations that influence their development, such as age, morbidity caused by the treatment, as well as different psychosocial variables ${ }^{(14,15)}$. The most discussed predictors in the literature are the perception of situation as a stressor, perception of social support, use of adaptive coping strategies and use of rumination ${ }^{(16)}$. 
Rumination deals with a cognitive process where the individual establishes himself in a self-reflexive movement in a passive and repetitive way. It is a form of response to stress where the person fixes on the problem and on the negative feelings, but without defining assertive resolution strategies ${ }^{(17)}$. In general, rumination deals with a non-adaptive coping strategy since it encourages negative symptomatology ${ }^{(18)}$. Coping strategies are the different ways people deal with stressful situations ${ }^{(19)}$. Patients with different types of cancer have their coping strategies directly linked to their perception of the disease ${ }^{(20)}$.

Social support is a concept understood as multidimensional since it refers to the emotional, financial and material resources that the individual accesses through social environment ${ }^{(21)}$. Sidney $\mathrm{Cobb}^{(22)}$ developed a model that establishes that the individual internalizes social support based on three beliefs: to be loved and know that there are people who care about well-being, to be valued and to belong to a social network.

Although the predictors have already been evaluated in studies in different cultures, systematic reviews and/or meta-analyzes about the subject are not found in the literature. Thus, this study searches systematically compile articles that evaluate rumination and/or social support as predictors of PTG in populations of women with breast cancer, analyzing the results presented in a narrative form.

\section{Methods}

\section{Search, selection and review strategies}

The protocol of this review is registered in PROSPERO under registration number CRD42017060584. The PRISMA guideline items were followed for systematic reviews and meta-analyzes, from the search for articles, extraction of results and description of the systematic process.

The Embase, Web of Science, PsycInfo, Scopus and Cochrane Online Library databases were used. It was searched for empirical studies with quantitative methodology, which evaluated PTG, social support and/or rumination in populations of women with breast cancer. From the inclusion criteria, PTG evaluation must be performed using some sort of quantitative measure. The selected papers were published until September 2017.

According to the specificities of each base, the search strategy used and the Boolean connectors were: ("posttraumatic growth" OR "posttraumatic growth inventory") AND ("breast cancer") AND ("social support") OR (rumination). The last search date for articles was conducted on October 19th, 2017. Articles found in the list of references were included. These articles were not identified in the searches, but met the inclusion criteria stipulated.

Figure 1 describes the process of searching and analyzing the articles. After the manual survey, two independent judges evaluated the abstracts in order to minimize publication bias. A third judge was invited to evaluate disagreements regarding the selection of abstracts and to the reading of full articles. If there was still disagreement in the inclusion or exclusion of the abstract, the article was fully read. From the selection of articles to the reading of the full articles, after applying the inclusion and exclusion criteria, Covidence software developed by Cochrane was used to reduce the risk of bias and to evaluate the studies by the judges. 
In the reading of the abstracts, 163 papers were excluded for not meeting the pre-established inclusion criteria. 74 duplicates were also excluded. 24 articles were eligible for complete reading by two judges. One was excluded because the text was not available in English. Six were excluded due to not being articles, but expanded abstracts instead. Other three articles were excluded in the complete reading because they didn't correspond to other including criteria. In the end, two other articles were excluded because they were not fully available online.

Figure 1. Flow Diagram based on Prisma Statement.

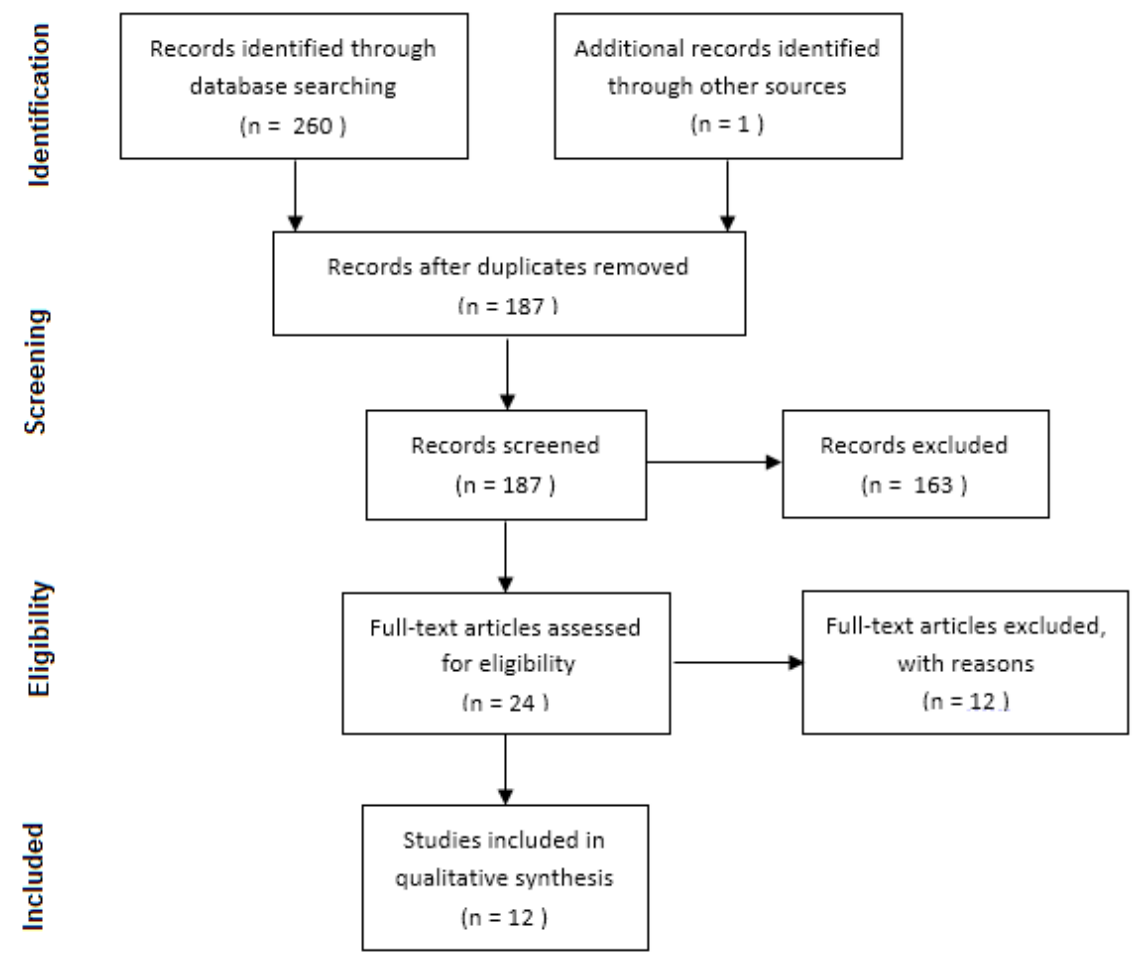

\subsection{Data extraction}

After applying the inclusion and exclusion criteria, 24 papers were considered eligible for this review, among the 187 abstracts analyzed. After the exclusion of articles that did not correspond to the including criteria, as well as one that was unavailable in English and two that were not fully available, 12 studies were left. Two judges extracted key data from the articles in order to conduct a qualitative analysis of general information as a result of the researches. The Crowe Critical Appraisal Tool (CCAT) was also used as an assessment measure to quantify the quality of the studies' methodology ${ }^{(23)}$.

Two articles are from the same longitudinal study. Although the data of the applied instruments are the same, none was excluded. Each article focuses on different important aspects for the discussion of the results (table 1). 


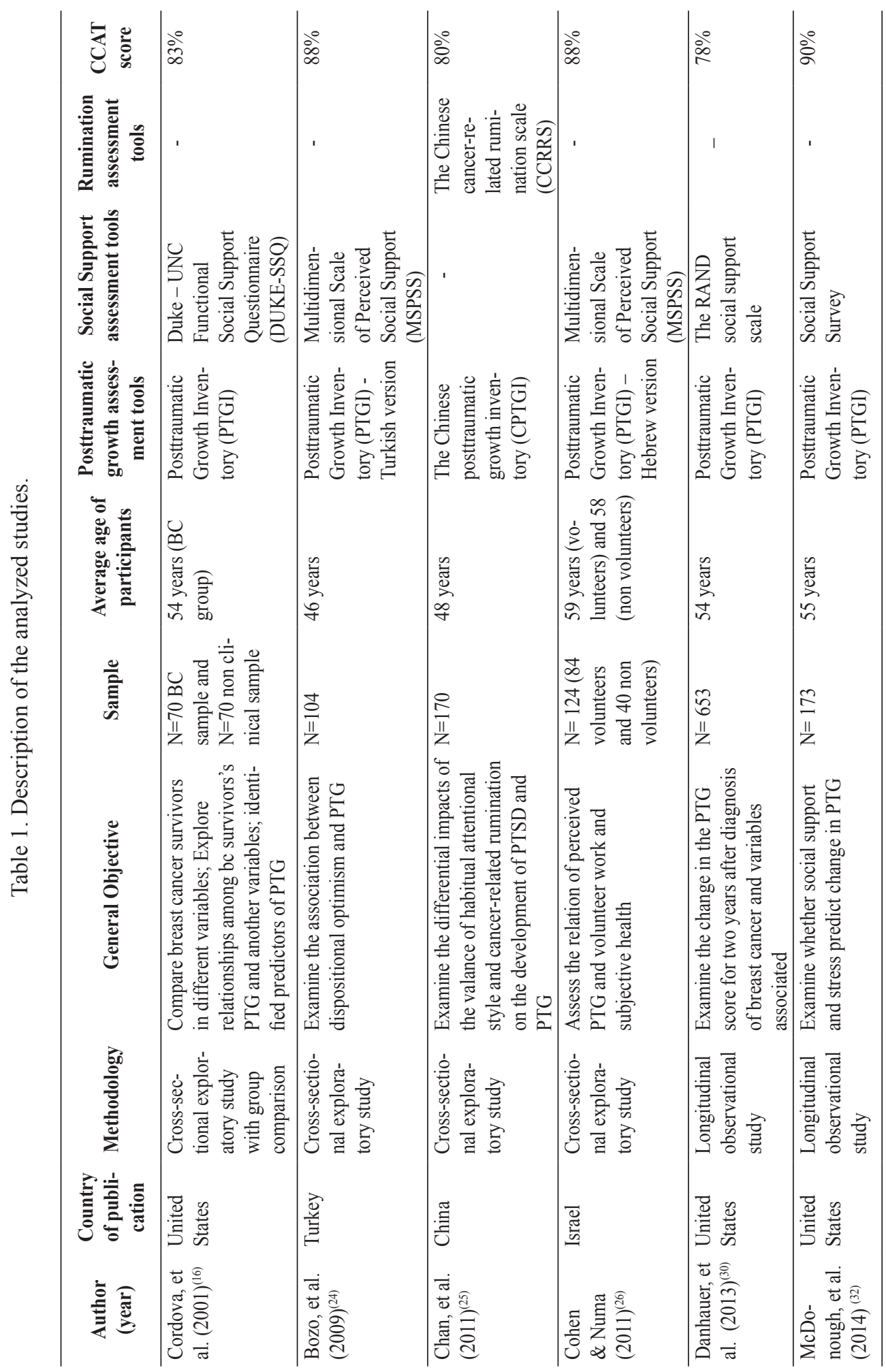




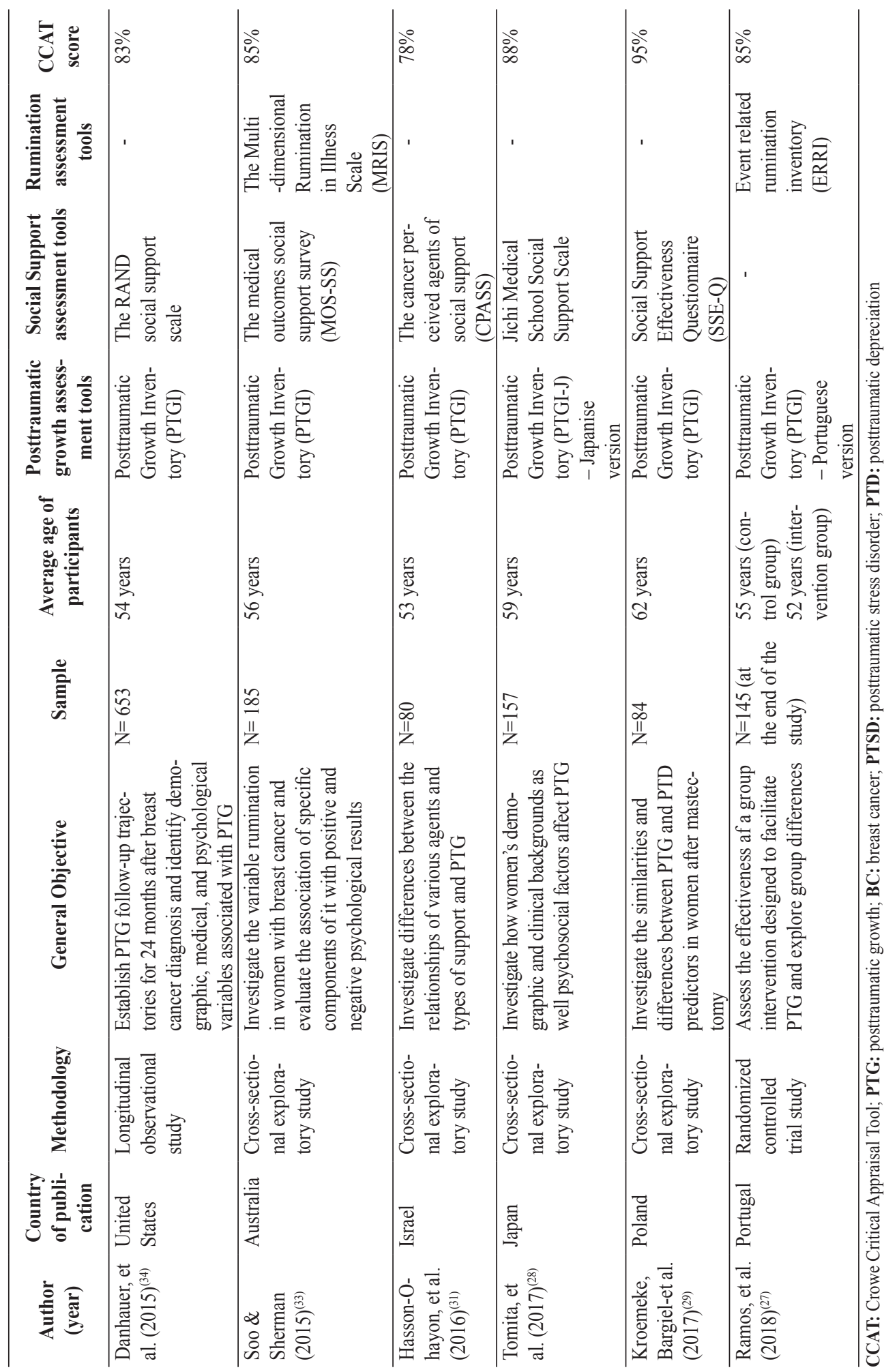




\section{Results}

\section{Methodological Quality}

The score average of the studies analyzed through CCAT was of $85 \%$ (range $78 \%$ $95 \%$ ). There were no studies with low methodological quality. However, there were found no articles that would reach $100 \%$ on the final score (see table 1).

\section{Posttraumatic growth}

From the analyzed studies, five opted to use cultural adaptions of the original PTGI ${ }^{(24-}$ 28). Only in the studies of Chan et al. ${ }^{(25)} \mathrm{e}$ Tomita et al. ${ }^{(28)}$ the adapted instruments went through alterations in the amount of items and factors. However, the authors quote having reached good indexes of reliability.

All studies stated to have found significant PTG scores in their samples. Despite of them all having evaluated women with breast cancer, there were some differences in the samples' characteristics. Kroemeke et al. ${ }^{(29)}$ focused the investigation in women who had undergone mastectomy. The study of Cohen and Numa ${ }^{(26)}$, on the other hand, looked to compare PTG between women who had and who had not engaged in volunteering.

PTG was correlated with time after diagnosis, showing more significant growth in the first 12 months, tending to stabilize after ${ }^{(30)}$. In addition, it was still positively correlated with optimism ${ }^{(24)}$. Women who reported having a religion had higher scores than those who did not report ${ }^{(25,28)}$. Samples that reported worse health presented lower PTG scores compared to women with fewer side effects ${ }^{(26)}$.

\section{Social Support}

The social support variable was evaluated in ten studies. Different outcomes were presented for this variable. One study had as its main objective the correlation between social support and $\mathrm{PTG}^{(24)}$. The authors concluded that the sources of social support that most contribute to PTG are global, familiar, friendly, and spouse support. However, on another study with the main objective focusing on PTG and social support ${ }^{(31)}$, the initial hypothesis were not confirmed. Only cognitive support showed to be predictor of PTG in the regressive model established by the authors, whereas spouse support did not show any association.

Regardless of how almost all studies that included social support on their analysis concluded that there is a positive correlation between this variable and PTG, there was no consensus. On the study of Kroemeke et al. ${ }^{(29)}$, social support showed no correlation with PTG, and was therefore not included on the model tested for predictor analysis. On the other hand, on the study of Tomita et al. ${ }^{(28)}$ the variable only affected the factor relating to others, being important especially when coming from one's spouse.

Social support directly related to breast cancer was shown to be a predictor of positive change in the PTG score. However, general social support was not a predictor $^{(32)}$. Yet in Cohen and Numa's ${ }^{(26)}$ study, no significant correlation was found between PTG and perceived social support. These authors suggest that previous studies with similar results also evaluated samples with longer time after diagnosis. 
Furthermore, perceived social support was related to other variables. In Tomita et al. ${ }^{(28)}$ study, social support was related to the reduction of depressive symptoms, as well as in the McDonough et al. ${ }^{(32)}$ study, it showed positive correlation with subjective well-being.

\section{Rumination}

Three articles evaluated and analyzed rumination in their samples. In two studies this variable was included in the main objective ${ }^{(25,33)}$, and in one it was used as a benchmark variable of differences between compared groups ${ }^{(27)}$.

On the studies found there is a consensus of rumination being a variable positively correlated to PTG. However, there are differences in the types of rumination. Ramos et al. ${ }^{(27)}$ point out that only deliberate rumination showed correlation with PTG. On the study of Soo and Sherman ${ }^{(33)}$, however, the factors Intrusion, Instrumentality e Brooding correlated to different factors of PTGI, while the subscale instrumental rumination correlated with all five factors of PTGI.

Chan et al. ${ }^{(25)}$ indicate that there are differences between positive and negative cancer related rumination. The first was positively associated with PTG scores. Furthermore, it can also mediate the relationship between PTG and positive attentional bias. Meanwhile, negative cancer related rumination was significantly related to posttraumatic stress disorder (PTSD) symptoms.

\section{Discussion}

This review presented data regarding the evaluation of PTG in women with breast cancer in studies that also evaluated social support and/or rumination as predictors. Until now, no systematic review has been published worldwide presenting the same objective. However, the results presented here should be considered with caution since there are important methodological differences in the analyzed articles.

All the studies considered in this review reported finding PTG scores in the samples, understanding that it is possible to perceive a positive change in life, even after the experience of breast cancer. In the study by Cordova et al. ${ }^{(16)}$, equivalent values were found in the total score between the groups, and the group with breast cancer presented higher averages in the Relationship with Others, Spiritual Change and Life Appreciation factors. It is perceived as a stressful and traumatic situation for women in different aspects, which can result in symptoms such as depression, anxiety and acute stress $^{(12,13)}$. The identification of the possibility of developing positive changes after such situation allows the development of different interventions in mental health, focusing specifically on quality of life. In addition, the study of predictors that facilitate the development of PTG supports in the improving of the model.

Social support was evaluated in ten analyzed studies. The instruments used in the evaluations were composed of different subscales, evaluating different aspects. In the study by Soo and Sherman ${ }^{(33)}$ the focus of evaluation was not the social support, which is included as an affective variable. Although the authors concluded that social support had a direct influence on the model established between rumination and PTG. Thus, it is suggested that the social factor is determinant for the development of PTG when combined with other predictors. The subscale 
emotional/informational social support demonstrated correlations with the PTG score. It is understood that the possibility of expression allows the evaluation of different perspectives of the problem. In the study by Danhauer et al. ${ }^{(34)}$ it was observed that women who presented positive scores in different predictor variables, but low social support index, also presented no increase in PTG. It is understood the importance of psychosocial support during coping with breast cancer, corroborating the already established model of $\mathrm{PTG}^{(1)}$.

It is important to point out that there were different results regarding types and sources of social support. Two of the analyzed studies found that spouse support is positively correlated to a greater PTG ${ }^{(24,28)}$. However, on the study of Hasson-Ohayon et al. ${ }^{(31)}$, where this was one of the hypothesis, it was not confirmed. The authors found in their results that the cognitive type of social support was the most significant one in the models, something that had already been seen in other analysis ${ }^{(26)}$. As for the study of McDonough et al. ${ }^{(32)}$, evaluation of social support specifically tied to breast cancer showed to be a predictor of change on PTG, but general social support did not. Thus, it is important to analyze carefully the different types and sources of social support in different populations, given that this seems to be a variable that can be presented in distinct ways. In the discussion of results, Danhauer et al. ${ }^{(30)}$ bring forward considerations regarding the model found in the study. The authors search to establish a causal relationship where social support assumes to facilitate the development of PTG. However, after the analysis the author questioned whether the reverse would also occur or whether the development of PTG would facilitate an increase in the perception of social support. From the considerations of the study, PTG presupposes positive changes, as Relationship with Others and a predictor of greater social support after the stressful situation. Thus, positive change would be influenced by social support, and the occurrence of positive changes would facilitate interpersonal interaction, being variables that feedback each other.

It is known that social support allows rumination to occur deliberately since it offers a space where the person can discuss the traumatic and/or stressful situation ${ }^{(2)}$. The social support also serves as support for rumination, allowing it to occur in a healthy way. The emotional/informational factor of the MOS instrument was important in the model described by Soo and Sherman ${ }^{(33)}$, where rumination and PTG were associated. Thus, direct interference of both variables in PTG scores is observed.

Considering rumination as a variable, if women repeatedly speak about their experience with other people, it is possible to present a positive effect on the understanding and assimilation of the situation. Thus, occurring the perception of positive changes. The social support is shown as an important component, when considered by the woman, either as family, friends or others. In this case, an important resource will be therapeutic groups, which allow the exchange of experiences between people who have similar characteristics, offering social support and information ${ }^{(35,36)}$.

Rumination is associated in different studies of depressive and stress symptoms ${ }^{(37,38)}$. However, studies evaluating PTG and rumination have concluded that the last may facilitate the perception of positive changes after adverse experiences ${ }^{(16,25,27,33,39)}$. It is emphasized that subscales that treated with reflexive rumination, an active processing form, were more predictive of PTG scores ${ }^{(25,33)}$. Findings showed that negative cancerrelated rumination partially mediated the relationship between negative attentional bias and PTSD symptoms, while positive cancer-related rumination partially mediated the relationship between positive attentional bias and PTG. This active processing may be purposeful, allowing the elaboration of coping strategies. 
Tedeschi and Calhoun ${ }^{(2)}$ described that the act of actively speaking about the stressful situation results in the remodeling of mental schemas that were affected by the situation in question. Thus, it is understood that the more the people thinks actively about the situation and looks for ways to re-signify it, the greater PTG it can experience. Chan et al. ${ }^{(25)}$ suggest that active and growth-oriented strategies are understood as positive rumination. The authors also point out that negative thinking and recurrent fear of cancer are linked to symptoms such as PTSD and depression and are classified as negative rumination. These are corroborated by the study by Morris and ShakespeareFinch $^{(40)}$, which evaluating sample of participants with different cancers, find in their results that deliberately ruminating on benefits is positively related to PTG. Thus, we conclude that there is a complex difference in the type of rumination that results in personal growth after a stressful situation. Negative rumination strategies can result in the facilitation of negative symptoms, hindering the perception of growth and benefits.

It is worth mentioning that, although they did not evaluate rumination directly, Danhauer et al. ${ }^{(30)}$ considered that PTG may be facilitated if there is any degree of tolerance regarding intrusive thoughts during treatment. In this way, it is possible to consider interventions that instigate rumination in an active way, where the patient is encouraged to speak and relive the situation consciously, directed to an adaptive path, developing positive coping strategies. On the other hand, in Cordova et al. ${ }^{(16)}$ the authors did not mention specifically the term rumination. However, the sample of women with breast cancer was evaluated with the instrument Talking About Cancer, which seeks to evaluate how much the person speaks about what happened. Despite the authors not mentioning specifically the concept of rumination, their results conclude that the active speech about cancer showed a high correlation with greater scores of PTG.

The articles analyzed used different methodologies. Data collection from the Soo and Sherman ${ }^{(33)}$ survey occurred via internet, with participants chosen for convenience. However, the authors do not discuss whether a pilot study was conducted or whether there was a possible sample loss for the time required for evaluation. It is known that the longer the computer is used the less ability to maintain attention in a single task ${ }^{(41)}$. Thus, it is considered important a careful evaluation of the size and the quantity of the instruments inserted in online surveys, in order to reduce possible sample loss. The application of a pilot study can be an effective way to evaluate if the survey was well constructed, considering the form of data collection. However, on the study of Cohen and $\mathrm{Numa}^{(26)}$, the participants received and returned the instruments via email. That way, it becomes harder to control any bias on the answers, which can interfere with the trustworthiness of the obtained results.

It is noticed the use of self-report scales and limitation, answered based on the perception that individual has of himself. In this way, responses are more likely to be biased. Regarding the objective of these studies, this type of evaluation is the one which best applies since it aims to measure self-perceived changes.

Two articles analyzed in this study ${ }^{(30,34)}$ are from the same longitudinal study. There was no exclusion since each article scored a different objective and discussed different aspects raised in the research. Their results derive from the same data collection, with the same sample. It is understood that these articles cannot be better explored, making generalization difficult.

In this review, four longitudinal studies were found and only one presented an intervention protocol ${ }^{(27)}$. In this research, quantitative measures were used to evaluate the rumination variable. The authors observed that the participants in the clinical 
group presented higher rates of PTG compared to participants in the control group, concluding that the intervention tested was effective. In addition, intrusive rumination was a moderating variable of PTG.

The empirical evidence of the data presented from intervention protocols is extremely important, applied in everyday clinical practice. It is understood that interventions tested empirically are more effective, reflecting in the improvement of care provided.

The studies analyzed in this review presented expressive samples, but homogeneous. The fact that participants presented no distinct characteristics may influence the results, such as social class and educational level. It is important to replicate the studies, evaluating PTG, social support and rumination, as well as others predictor variables in heterogeneous samples, measuring whether positive change may occur in different cultures and social levels.

Despite the methodological and objective differences, the results of the studies analyzed corroborate the theoretical model of $\mathrm{PTG}^{(1,2)}$. The standard deviations of the overall mean total PTGI score in four times of the study by Danhauer et al. ${ }^{(30)}$, Soo and Sherman ${ }^{(33)}$ and Cordova et al ${ }^{(16)}$ are high, being respectively $\mathrm{SD}=23.12, \mathrm{SD}=$ 20.58 e $\mathrm{SD}=24.8$ for the clinical group and $\mathrm{SD}=26.3$ for the control group. Thus, the results analyzed should be interpreted with caution since the standard deviation departs considerably from the mean. However, in all three studies PTG presented a positively and relatively stable variable.

\section{Conclusions}

In clinical terms, this review allows reflection on different mental health interventions. Considering rumination and the specific aspect related to the perception of positive changes after breast cancer, it is understood that the influence in this model allows the therapist to conduct interventions assertively. Thus, rumination does not follow a path of free association. The therapist can assist the patient to relive the situation in a way that encourages a positive re-signification of the stressor.

\section{Study Limitations}

Further studies are suggested on this methodological model in order to expand the publication time criteria and to include published studies in the emergence and initial understanding of the PTG. It is suggested a meta-analysis of the results found in the studies, in order to confirm the hypotheses described through quantitative methods. Moreover, the use of a standardized instrument for a qualitative analysis of the results of the studies found is suggested.

\section{References}

1. Tedeschi RG, Calhoun LG. The posttraumatic growth inventory: Measuring the positive legacy of trauma. J Trauma Stress 1996;9:455-71. doi: 10.1007/BF02103658

2. Tedeschi RG, Calhoun LG. Posttraumatic growth: Conceptual foundations and empirical evidence. Psychol Inq 2004;15:1-18. doi: 10.1207/s15327965pli1501_01 
3. Dirik G, Karanci AN. Variables related to posttraumatic growth in Turkish Rheumatoid Arthritis Patients. J Clin Psychol Med Settings 2008;15:193-203. doi: 10.1007/s10880008-9115-X

4. Holtmaat K, Spek N van der, Cuijpers P, Leemans CR, Leeuw IMV. Posttraumatic growth among head and neck cancer survivors with psychological distress. Psychooncology 2016; 26:96-101. doi: 10.1002/pon.4106

5. Ho S, Rajandram RK, Chan N, Samman N, McGrath C, Zwahlen RA. The roles of hope and optimism on posttraumatic growth in oral cavity cancer patients. Oral Oncol 2011;47:121-4. doi: 10.1016/j.oraloncology.2010.11.015

6. Barthakur MS, Sharma MP, Chaturvedi SK, Manjunath SK. Posttraumatic growth in women survivors of breast cancer. Indian J Palliat Care 2016;22:157-62. doi: 10.4103/0973-1075.179609

7. Baník G, Gajdosová B. Positive changes following cancer: posttraumatic growth in the context of other factors in patients with cancer. Support Care Cancer 2014;22: 2023-9. doi: 10.1007/s00520-014-2217-0

8. Gianinazzi ME, Rueegg CS, Vetsch J, Lüer S, Kuehni CE, Michel G. Cancer's positive flip side: posttraumatic growth after childhood cancer. Support Care Cancer 2016;24: 195-203. doi: 10.1007/s00520-015-2746-1

9. World Health Organization - WHO. Cancer. [Internet]. Genebra: The Organization; 2018; 2018 Jan 15 [cited 2018 Abril 02]. Available from: http://www.who.int/cancer/en/

10. Bidstrup PE, Christensen J, Mertz BG, Rottmann N, Dalton SO, Johansen C. Trajectories of distress, anxiety and depression among women with breast cancer: looking beyond the mean. Acta Oncol 2015;54:789-96. doi: 10.3109/0284186X.2014.1002571

11. Hutter N, Vogel B, Alexander T, Baumeister H, Helmes A, Bengel J. Are depression and anxiety determinants or indicators of quality of life in breast cancer patients? Psychol Health Med 2013;18:412-9. doi: 10.1080/13548506.2012.736624

12. Stafford L, Komiti A, Bousman C, Judd F, Gibson P, Bruce Mann G, Quinn M. Predictors of depression and anxiety symptom trajectories in 24 months following diagnosis of breast or gynaecologic cancer. Breast 2016;26:100-5. doi: 10.1016/j.breast.2016.01.008

13. Maass SWMC, Roorda C, Berendsen AJ, Verhaak PFM, de Bock GH. The prevalence of long-term symptoms of depression and anxiety after breast cancer treatment: a systematic review. Maturitas 2015;82:100-8. doi: 10.1016/j.maturitas.2015.04.010

14. Boyle CC, Stanton AL, Ganz PA, Bower JE. Posttraumatic growth in breast cancer survivors: does age matter?. Psychooncology 2016;1:1-8. doi: 10.1002/pon.4091

15. Lelorain S, Bonnaud-Antignac A, Florin A. Long term posttraumatic growth after breast cancer: prevalence, predictors and relationships with psychological health. J Clin Psychol Med Settings 2010;17:14-22. doi: 10.1007/s10880-009-9183-6

16. Cordova MJ, Cunningham LLC, Carlson CR, Andrykowski MA. Posttraumatic growth following breast cancer: A controlled comparison study. Health Psychol 2001;20:176-85. doi: 10.1037/0278-6133.20.3.176

17. Nolen-Hoeksema S, Wisco BE, Lyubomirsky S. Rethinking Rumination. Perspect Psychol Sci 2008;3:400-24. doi: 10.1111/j.1745-6924.2008.00088.x

18. Lyubomirsky S, Nolen-Hoeksema S. Self-perpetuating properties of dysphoric rumination. J Pers Soc Psychol 1993;65:339-49. doi: 10.1037/0022-3514.65.2.339

19. Carver CS, Scheier MF. Assessing coping strategies: a theoretically based approach. J Pers Soc Psychol 1989;56:267-83. doi: 10.1037/0022-3514.56.2.267

20. Hopman P, Rijken M. Illness perceptions of cancer patients: relationships between illness characteristics and coping. Psychooncology 2015;24:11-8. doi: 10.1002/pon.3591 
21. Siqueira MMM. Construção e validação da escala de percepção de suporte social. Psicol Estud 2008;13:381-8. doi: 10.1590/S1413-73722008000200021

22. Cobb S. Social support as a moderation of life estress. Psychosom Med 1976;38:300-14. doi: 10.1097/00006842-197609000-00003

23. Crowe M, Sheppard L, Campbell A. Reliability analysis of a proposed critical appraisal tool demonstrated value for diverse research designs. J Clin Epidemiol 2012;65:375-83. doi: 10.1016/j.jclinepi.2011.08.006

24. Bozo Ö, Gündogdu E, Büyükasik-Çolak C. The moderating role of different sources of perceived social support on the dispositional optimism- posttraumatic growth relationship in postoperative breast cancer patients. Health Psychol 2009;14:1009-20. doi: $10.1177 / 1359105309342295$

25. Chan MWC, Ho SMY, Tedeschi RG, Leung CW. The valance of attentional bias and cancer-related rumination in posttraumatic stress and posttraumatic growth among women with breast cancer. Psychooncology 2011;20:544-52. doi: 10.1002/pon.1761

26. Cohen M, Numa M. Posttraumatic growth in breast cancer survivors: a comparison of volunteers and non-volunteers. Psychooncology 2011;20:69-76. doi: 10.1002/pon.1709

27. Ramos C, Costa PA, Rudnicki T, Marôco AL, Leal I, Guimarães R, Fougo JL, Tedeschi RG. The effectiveness of a group intervention to facilitate Posttraumatic Growth among women with breast cancer. Psychooncology 2018;27:258-64. doi: 10.1002/pon.4501

28. Tomita M, Takahashi M, Tagaya N, Kakuta M, Kai I, Muto T. Structural equation modeling of the relationship between posttraumatic growth and psychosocial factors in women with breast cancer. Psychooncology 2017;26:1198-204. doi: 10.1002/pon.4298

29. Kroemeke A, Bargiel-Matusiewicz K, Kalamarz M. Mixed psychological changes following mastectomy: unique predictors and heterogeneity of post-traumatic growth and post-traumatic depreciation. Front Psychol 2017;8:1-9. doi: 10.3389/fpsyg.2017.01245

30. Danhauer SC, Case LD, Tedeschi R, Russell G, Vishnevsky T, Triplett K, et al. Predictors of posttraumatic growth in women with breast cancer. Psychooncology 2013;22:267683. doi: 10.1002/pon.3298

31. Hasson-Ohayon I, Tuval-Mashiach R, Goldzweig G, Levi R, Pizem N, Kaufman B. The need for friendships and information: dimensions of social support and posttraumatic growth among women with breast cancer. Palliat Support Care 2016;14:387-92. doi: $10.1017 / \mathrm{S} 1478951515001042$

32. McDonough MH, Sabiston CM, Wrosch C. Predicting changes in posttraumatic growth and subjective well-being among breast cancer survivors: the role of social support and stress. Psychooncology 2014;23:114-20. doi: 10.1002/pon.3380

33. Soo H, Sherman KA. Rumination, psychological distress and post-traumatic growth in women diagnosed with breast cancer. Psychooncology 2015;24:70-9. doi: 10.1002/ pon.3596

34. Danhauer SC, Russell G, Case D, Sohl AJ, Tedeschi RG, Addington EL, et al. Trajectories of posttraumatic growth and associated characteristics in women with breast cancer. Ann Behav Med 2015;49:650-9. doi: 10.1007/s12160-015-9696-1

35. Hulbert-Williams NJ, Storey L, Wilson KG. Psychological interventions for patients with cancer: psychological flexibility and the potential utility of Acceptance and Commitment Therapy. Eur J Cancer Care (Engl) 2015;24:15-17. doi: 10.1111/ecc.12223

36. Thomas LPM, Meier EA, Irwin SA. Meaning-centered psychotherapy: a form of psychotherapy for patients with cancer. Curr Psychiatry Rep 2014;16: 488. doi: 10.1007/ s11920-014-0488-2 
37. Liu J, Peh CX, Mahendran R. Body image and emotional distress in newly diagnosed cancer patients: the mediating role of dysfunctional attitudes and rumination. Body Image 2017;20:58-64. doi: 10.1016/j.bodyim.2016.11.001

38. Steiner JL, Wagner CD, Bigatti SM, Storniolo AM. Depressive rumination and cognitive processes associated with depression in breast cancer patients and their spouses. Fam Syst Health 2014;32:378-88. doi: 10.1037/fsh0000066

39. Hirooka K, Fukahori H, Taku T, Togari T, Oqawa A. Quality of death, rumination, and posttraumatic growth among bereaved family members of cancer patients in home palliative care. Psychooncology 2017;1-7. doi: 10.1002/pon.4446

40. Morris BA, Shakespeare-Finch J. Rumination, post-traumatic growth, and distress: structural equation modelling with cancer survivors. Psychooncology, 2011;20:1176-83. doi: $10.1002 /$ pon. 1827

41. Vujic A. Switching on or switching off? Everyday computer use as a predictor of sustained attention and cognitive reflection. Computers in Human Behavior 2017;72:152-62. doi: 10.1016/j.chb.2017.02.040 